\title{
Magnetic resonance imaging is the future of transcatheter aortic valve replacement implantation ... and always will be
}

\author{
John Conte, MD
}

\author{
From the Division of Cardiac Surgery, Department of Surgery, Johns Hopkins Medical Institutions, Baltimore, \\ Md. \\ Disclosures: Author has nothing to disclose with regard to commercial support. \\ Received for publication Dec 6, 2015; accepted for publication Dec 7, 2015; available ahead of print Jan 15, 2016. \\ Address for reprints: John Conte, MD, Division of Cardiac Surgery, Department of Surgery, Zayed Tower, Suite \\ 7107, The Johns Hopkins Hospital, 1800 Orleans St, Baltimore, MD 21287 (E-mail: jconte@jhmi.edu). \\ J Thorac Cardiovasc Surg 2016;151:1278-9 \\ $0022-5223 / \$ 36.00$ \\ Copyright (C) 2016 by The American Association for Thoracic Surgery \\ http://dx.doi.org/10.1016/j.jtcvs.2015.12.004
}

During its short time in the medical lexicon, transcatheter aortic valve replacement (TAVR) has been as disruptive a medical technology as we have seen since the heart-lung machine. It has become the ideal treatment of aortic stenosis in patients with native and prosthetic aortic valve stenosis who are considered to be at high risk and are not considered to be operative candidates. It is being studied in patients at intermediate risk. It has been a gateway technology to the future treatment of valvular heart disease.

TAVR is performed in the cardiac catheterization laboratory (CL) or the hybrid operating room, and fluoroscopy is the primary method of imaging used to guide implantation. Early challenges facing TAVR include accurate sizing, vascular access, precise deployment, perivalvular leaking (PVL), and, oh yes, cost. Engineering has and will continue to work to make the devices smaller, more accessible, and less prone to PVL. The use of computed tomography to size the aortic annulus accurately has been a huge leap forward in and of itself, and echocardiography has become a procedural adjunct. $^{1,2}$

In this issue of the Journal, Miller and colleagues, ${ }^{3}$ working in the Cardiothoracic Research Laboratory at the National Institutes of Health, report their findings with the use of realtime magnetic resonance imaging (MRI) to guide TAVR with the Medtronic CoreValve (Medtronic, Inc, Minneapolis, Minn) with a modified delivery system. The National Institutes of Health group and others have extensively studied the use of MRI to deploy TAVR valves. ${ }^{4,5}$ The precision with which the valves are deployed in animal models is unquestioned. The successes of a number of well-done animal studies have led to a rising chorus of "MRIers" who believe that MRI is the road to TAVR perfection. ${ }^{6}$ One must keep in mind, however, that animal models all feature normal, nondiseased aortic valves. It is the irregularity of the calcified misshapen aortic annulus-aortic valve complex that is primarily responsible for PVL, not valve positioning. MRI sounds great, but let us look at the feasibility of using MRI to implant TAVR valves in 2016.

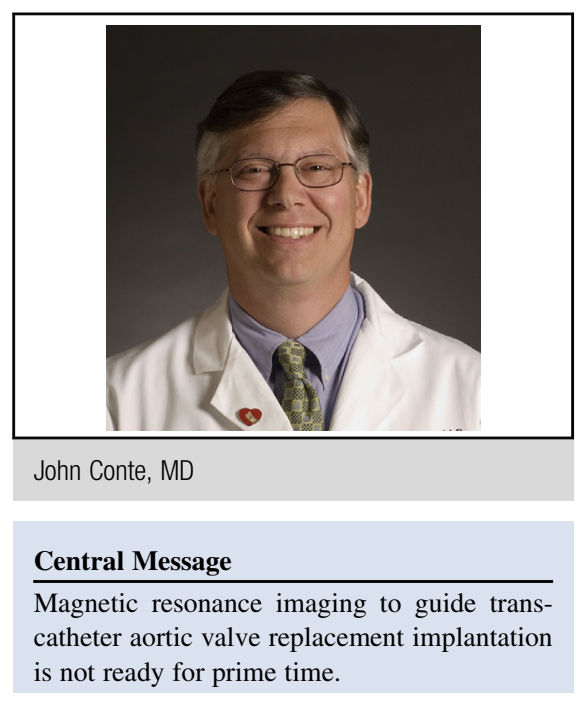

See Article page 1269 .

The current practice of TAVR has evolved from general anesthesia to local sedation with active patient management by anesthesiologists for patient safety and procedural efficacy. Implantation is performed in the CL or hybrid operating room, with fluoroscopy used for implantation and hemodynamic assessment, angiography, and echocardiography used for valve assessment. The standard CL imaging is ubiquitous in every hospital that has cardiology and cardiac surgery service, and although it is not without health risks, it is easy for health care providers to use, easy to work around, and relatively inexpensive. PVL is decreasing as generation 2 and 3 valves emerge and experienced teams with repositionable valves no longer have precision issues with deployment. Emergencies are handled immediately in the room where the TAVRs are performed. At Johns Hopkins, two-thirds of our patients now undergo their procedures with sedation by a multidisciplinary team, and there is a worldwide shift away from postop intensive care unit stays and toward outpatient procedures. All of these factors reduce cost through efficient resource use.

MRI is not widely available in patient care areas. It is currently neither patient nor provider friendly. The use of MRI is made even more unwieldy and creates additional patient safety issues by requiring the movement of intubated patients from room to room, as in the "state of the art" 
MRI-equipped CLs used in animal studies. Patients would have to be moved back again to the hybrid operating room "if" there were any emergencies. The movement of vulnerable patients between rooms is a nonstarter that should not require further discussion.

What about the immense costs of redesigning hospitals to accommodate MRI equipment and the costs of developing and producing MRI compatible equipment, TAVR valves, and delivery systems? The list can go on and on. To put it most succinctly, until such time that MRI equipment is ubiquitous, cost-effective and can allow a level of patient safety with an ease of health care provider interaction with the human patient equivalent to that of the current CL, MRI-guided TAVR implantation will be inferior to fluoroscopically guided implantation. To paraphrase Norman Shumway's often repeated statement regarding xenotransplantation, told to myself and a generation of residents hundreds of times,
"MRI-guided implantation is the future of TAVR . . . and always will be."

\section{References}

1. Hahn RT. Use of imaging for procedural guidance during transcatheter aortic valve replacement. Curr Opin Cardiol. 2013;28:512-7.

2. Zamorano JL, Gonçalves A, Lang R. Imaging to select and guide transcatheter aortic valve implantation. Eur Heart J. 2014;35:1578-87.

3. Miller JG, Li M, Mazilu D, Hunt T, Horvath KA. Real-time magnetic resonance imaging guided transcatheter aortic valve replacement. J Thorac Cardiovasc Surg. 2016;151:1269-77.

4. Horvath KA, Mazilu D, Cai J, Kindzelski B, Li M. Transapical sutureless aortic valve implantation under magnetic resonance imaging guidance: acute and short-term results. J Thorac Cardiovasc Surg. 2015;149:1067-72.

5. Kahlert P, Parohl N, Albert J, Schäfer L, Reinhardt R, Kaiser GM, et al Towards real-time cardiovascular magnetic resonance guided transarterial CoreValve implantation: in vivo evaluation in swine. J Cardiovasc Magn Reson. 2012;14:21.

6. Michler RE. Do the "eyes" have it? Lobbying for magnetic resonance imaging to guide transcatheter aortic valve deployment. J Thorac Cardiovasc Surg. 2015;149: 1072-3. 